\title{
Experimental Research on Mechanical Properties of Fiber Reinforcement Cement Stabilized Soil
}

\author{
Le JIANG ${ }^{1, a^{*}}$, Xing-Zhong WENG ${ }^{1, b}$, Bo-Han YANG ${ }^{1, c}$, Jun ZHANG ${ }^{1, d}$, \\ Jun-Zhong LIU ${ }^{1, e}$, Xiang-Cheng YAN ${ }^{2, f}$, Hua FANG ${ }^{3, g}$
}

${ }^{1}$ Department of Airfield and Building Engineering, Air Force Engineering University, Shanxi Xi'an, 710038, China

\author{
${ }^{2}$ PLA Unit 95746, Qionglai, 611531, China \\ ${ }^{3}$ PLA Unit 94969, Shanghai, 200436, China \\ ajl2553271@163.com, bwxz2626@sina.com, cyangbohan188@sina.com, dkgdzjtg@163.com, \\ eliujunzhong.ok@163.com, ${ }^{\mathrm{f}} \mathrm{yxc307@126.com,{ } ^ { 9 } 3 5 9 9 2 7 9 5 6 @ q q . c o m}$
}

${ }^{*}$ Corresponding author

Keywords: Fiber Reinforcement, Cement Stabilized Soil, Unconfined Compressive Strength, Failure Shapes.

\begin{abstract}
In order to investigate the strengthening mechanism of modified polypropylene fiber reinforcement cement stabilized soil (MPFRCSS), the unconfined compressive strength (UCS) was used to test the performance of soil with different fiber contents, different cement contents, and different maintaining conditions. The results indicated that the chemical effect (hydration reaction) of cement and physical effect (anti-crack effect) of fiber worked together, and the double reinforcement greatly improved the mechanical property of soil, especially for early strength, the UCS of soil increased form $1.21 \mathrm{MPa}$ to $4.42 \mathrm{MPa}$, the growth nearly 4 times. The appropriate contents of fiber should be $0.3 \%$ to $0.45 \%$. Through the observation of failure shapes, the soil showed an obviously brittle failure with the increased of cement content, and the failure mode would greatly changed from brittle failure to plastic failure with the incorporation of fiber.
\end{abstract}

\section{Introduction}

Soil used in highway engineering and airport engineering has the disadvantages of low strength, poor stability and poor durability. However, the performance might be improved by incorporation of cement, through a series of physical and chemical reaction of cement and soil, a new type of inorganic binding material, cement stabilized soil, was produced. Cement stabilized soil played an important role in highway engineering and airport engineering because of the good performance of the strength, stability and durability. It was widely applied in foundation reinforcement, waterproof curtain, slope reinforcement and deep foundation pit support[1]. However, recent researches[2] indicated that cement stabilized soil had serious shortcoming in crack resistance, the shrinkage deformation was large and it was easy to produce shrinkage crack. Therefore, the relevant construction technical standards[3] had set strict stipulation on using cement stabilized soil as base materials of airport and highway.

In order to enhance the ability of crack resistance, reinforced material was used in cement soil. Fiber reinforced material was a kind of macromolecule material[4-5] with high durability, high strength and high chemical corrosion resistance, it was widely used in concrete construction[6-8], but the application was less in cement stabilized soil field. Therefore, in this paper, cement stabilized soil incorporated with fiber reinforced material was researched and the unconfined compressive strength (UCS) of modified polypropylene fiber reinforcement cement stabilized soil (MPFRCSS) was discussed. The research results of reinforced effect and law of fiber to cement stabilized soil can be applied in highway and airport construction, and provided the reference for application of fiber reinforced technology. 


\section{Material and Test Method}

\section{Material}

(1) Soil. The test soil was sampled from a site of Xi'an city, it was the typical loess in the north area of China and the type of the soil was collapsible loess. The physical properties of test soil were shown in Table 1.

Tab. 1 Physical properties of test soil

\begin{tabular}{ccccc}
\hline \multirow{2}{*}{ Soil sample } & Liquid limit & Plastic limit & Plastic index & Maximum dry density \\
\cline { 2 - 5 } & $w_{\mathrm{L}} /(\%)$ & $w_{\mathrm{P}} /(\%)$ & $I_{\mathrm{P}}$ & $/\left(\mathrm{g} / \mathrm{cm}^{3}\right)$ \\
\hline collapsible loess & 38.2 & 23.4 & 14.8 & 1.887 \\
\hline
\end{tabular}

(2) Cement. The test cement was ordinary Portland cement (P.O 42.5R) and the density was 3.10 $\mathrm{g} / \mathrm{cm}^{3}$. The contents of cement $\left(w_{c}\right)$ were $6 \%, 8 \%$ and $10 \%$ by the percentage of the quality. The technical performance index was shown in Table 2.

Tab. 2 The technical performance index of cement

\begin{tabular}{ccccccc}
\hline \multirow{2}{*}{ cement grade } & \multicolumn{2}{c}{ setting time $/ \mathrm{h}$} & \multicolumn{2}{c}{ flexural strength /MPa } & \multicolumn{2}{c}{ compressive strength /MPa } \\
\cline { 2 - 6 } & Initial & Final & $3 \mathrm{~d}$ & $28 \mathrm{~d}$ & $3 \mathrm{~d}$ & $28 \mathrm{~d}$ \\
\hline $\mathrm{P} \cdot \mathrm{O} 42.5 \mathrm{R}$ & 2.16 & 5.16 & 6.41 & 8.94 & 29.7 & 51.7 \\
\hline
\end{tabular}

(3) Fiber. Polypropylene fiber (PF) was used as reinforced materials in this paper, and three fiber contents $\left(w_{f}=0.15 \%, 0.30 \%, 0.45 \%\right.$ by weight of dry soil) were used in the test, the basic parameters were shown in Table 3.

Tab.3 Basic parameters of PF

\begin{tabular}{cccc}
\hline Diameter $/ \mu \mathrm{m}$ & Tensile strength/MPa & Elasticity modulus $/ \mathrm{GPa}$ & Fusion point $/{ }^{\circ} \mathrm{C}$ \\
\hline $15 \sim 50$ & $>450$ & $>5.0$ & $\approx 160$ \\
\hline Length $/ \mathrm{mm}$ & Density $/ \mathrm{g} / \mathrm{cm}^{3}$ & Breaking elongation $/ \%$ & Burning point $/{ }^{\circ} \mathrm{C}$ \\
\hline 12 & 0.91 & $\geq 15$ & $\approx 580$ \\
\hline
\end{tabular}

Test

The UCS was the main index to measure the reinforcing and strengthening effect. In order to investigate the UCS of MPFRCS, test specimens (shown in Figure 1) were made into cylinder $(\Phi 50 \mathrm{~mm} \times 50 \mathrm{~mm})$, and before the test, specimens were divided into two groups(soak or dry maintaining) and respectively maintained for four different ages (0days, 3days, 7days, and 14 days). Then, according to the requirements of JTG E51-2009[4], specimens were tested on pavement material strength tester (PMST shown in Figure 2), and the UCS as well as the corresponding axial stress strain curve was obtained.

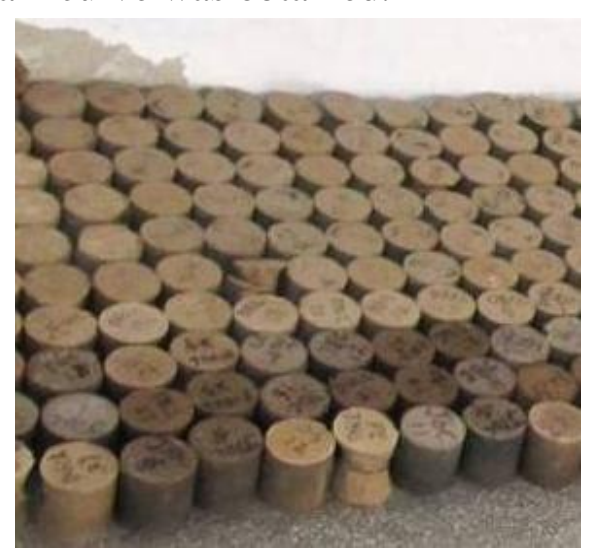

Fig. 1 Specimens in the test

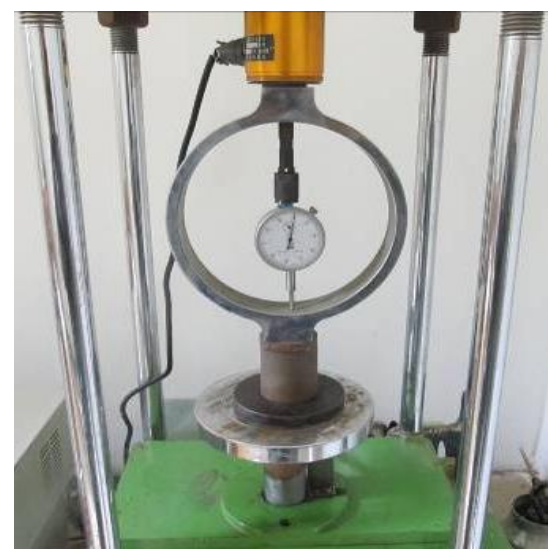

Fig. 2 The UCS tested on PMST 
In order to reduce the experimental error, and prevent stress concentration caused by surface uneven uplift, scraping knife was used to flat the surface of the sample. During the test, the sample should be placed at the center position of PMST, which made the weighing sensor, force measuring ring, upper pressing block, sample, under pressing block and the hemisphere at the same line. The UCS of the specimens were calculated according to Eq. 1.

$$
U C S=\frac{P}{A}
$$

Where $P$ is the peak pressure at failure and $A$ is the cross-sectional area of the specimen.

\section{Results and Discussion}

As discussed in section 2, MPFRCSS specimens were prepared by incorporating three cement contents and three fiber contents, and after soak maintaining for four different ages, the UCS of MPFRCSS specimens were obtained. Therefore, cement contents, fiber contents, and immersion time were discussed as influencing factors in this section, after further analysis of the experimental results, the enhancement mechanism was obtained.

\section{Effect of Cement Content on UCS}

In order to facilitate the analysis, kept fiber content $0.3 \%$ unchanged, and drawn the UCS curve with different maintaining ages and cement contents, as shown in Figure 3, the UCS of MPFRCSS generally increased with cement content increase, and the UCS of cement incorporated soil $\left(w_{c}=6 \%\right.$, $8 \%, 10 \%)$ were $4.24,4.55,5.5$ times higher than fiber only soil $\left(w_{c}=0 \%\right)$.

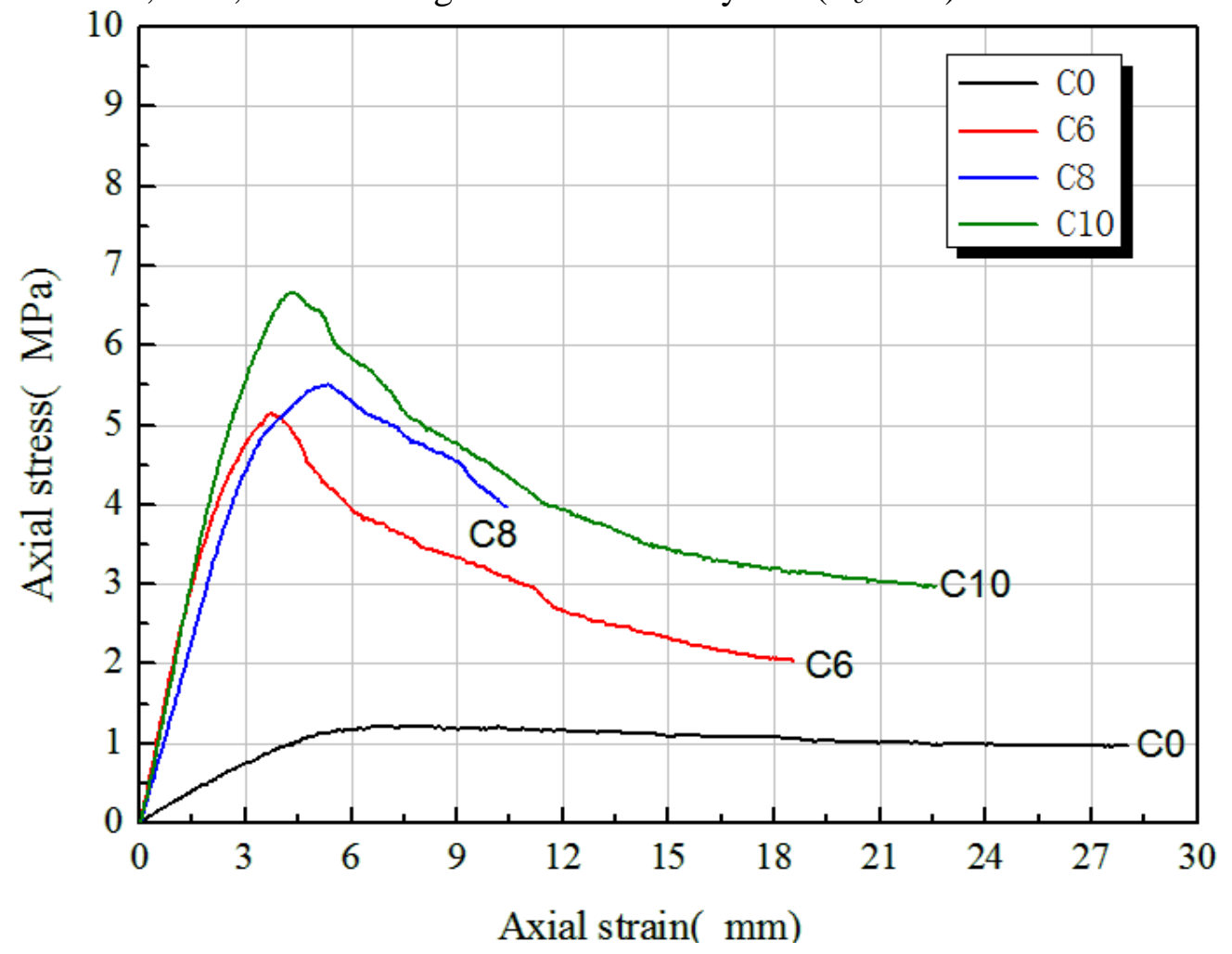

Fig. 3 The change of UCS with $w_{c}$

For fiber reinforced soil $\left(w_{c}=0 \%\right)$, the UCS of soil remained at a lower level, which generally at the range of $0.91 \sim 1.34 \mathrm{MPa}$. The water stability is so poor that the specimens started to collapse soon after immersed in water. Therefore, for these specimens, value of UCS had been deleted in Figure 3. After incorporation of fiber, the UCS as well as the water stability greatly enhanced, the 
value kept a 50 80\% growth. It indicated that the incorporation of fiber had changed the properties of the original soil.

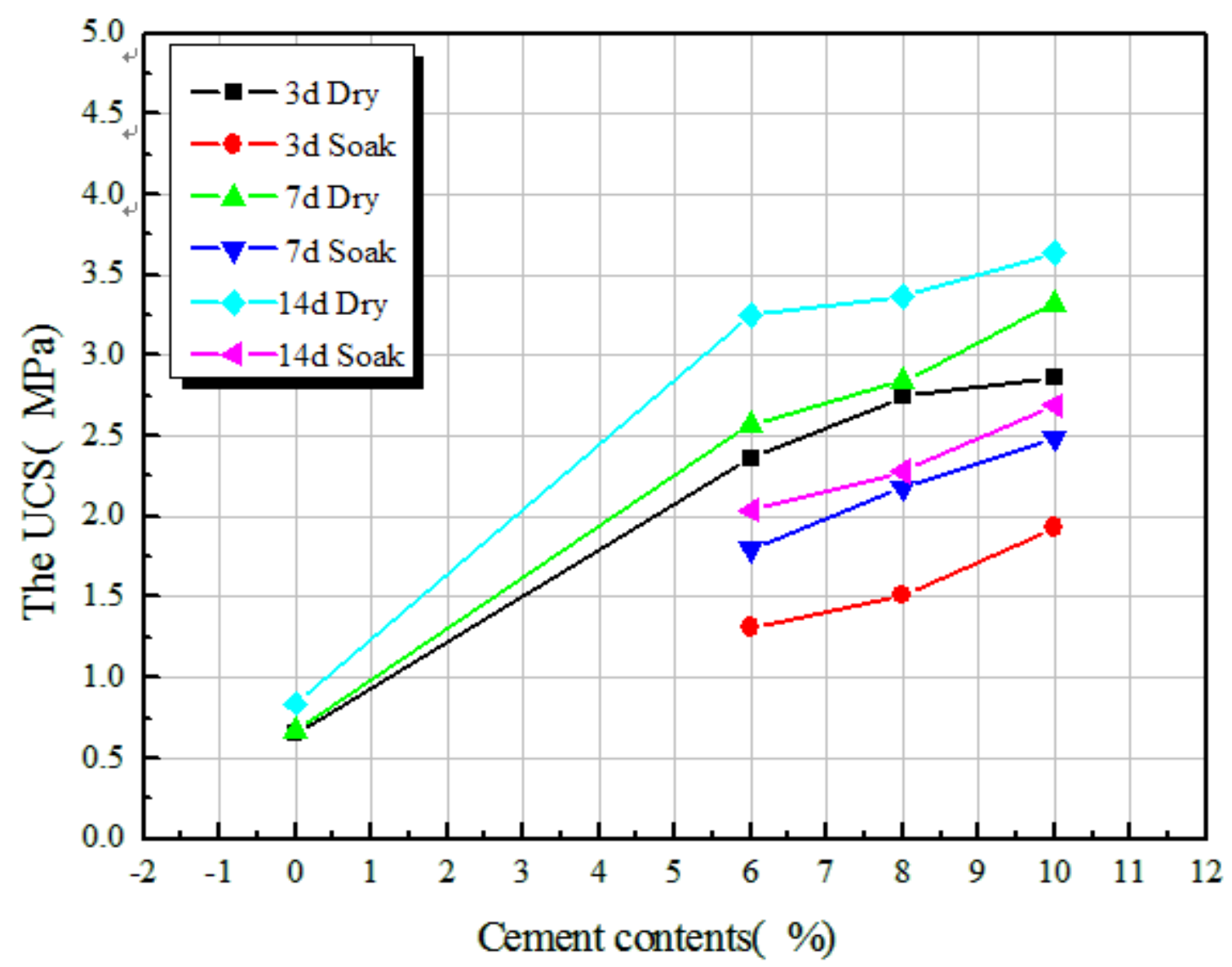

Fig. 4 The stress-strain curve of different $\mathrm{w}_{\mathrm{c}}$

Figure 4 was the stress strain curve of specimens with $0.3 \%$ fiber incorporation and under 7 days soak maintaining. The effect of incorporation of cement clearly presented by Figure 4, as seen in Figure 4 , the stress strain curve of cement incorporated $\left(w_{c}=6 \%, 8 \%, 10 \%\right)$ soil were significantly higher than the curve of fiber only soil $\left(w_{c}=0 \%\right)$, and the curve declined rapidly soon after achieving the peak value, which indicated the brittle failure characteristics of fiber only soil.

\section{Effect of Fiber on UCS}

With the increase of fiber contents, the UCS of soil presented a continuous increasing trend, take fiber only soil for example, as shown in Table 4, when the fiber contents increased from $0.15 \%$ to $0.45 \%$, the UCS of fiber only soil (under 7days dry maintaining) increased from $1.10 \mathrm{MPa}$ to $1.41 \mathrm{MPa}$, the growth was up to $28 \%$. When the cement contents was $10 \%$, with the fiber contents increased from $0.15 \%$ to $0.45 \%$, the UCS of cement incorporated soil (under 7days dry maintaining) increased from 5.48MPa to 7.40MPa, the growth was 35\%. As seen in Figure 5 and Figure 6, the UCS had been greatly increased with the incorporation of fiber, and the peak stress increased with the increasing of fiber contents. The initial period of stress strain curve of each specimen coincided well, and the curve was steep, the stress increasing rate is far greater than the rate of strain, which indicated that fiber enhanced the structure strength at initial stage. Compared the stress strain curve of different fiber contents, after the peak value, the stress strain curve of fiber soil $\left(w_{f}>0 \%\right)$ decreased more slowly than non-fiber soil $\left(w_{f}=0 \%\right)$, and the residual strength increased with the incorporation of fiber, which indicated that the failure mode trended from brittle failure to plastic failure with the incorporation of fiber. 
Tab. 4 The UCS with different cement and fiber contents

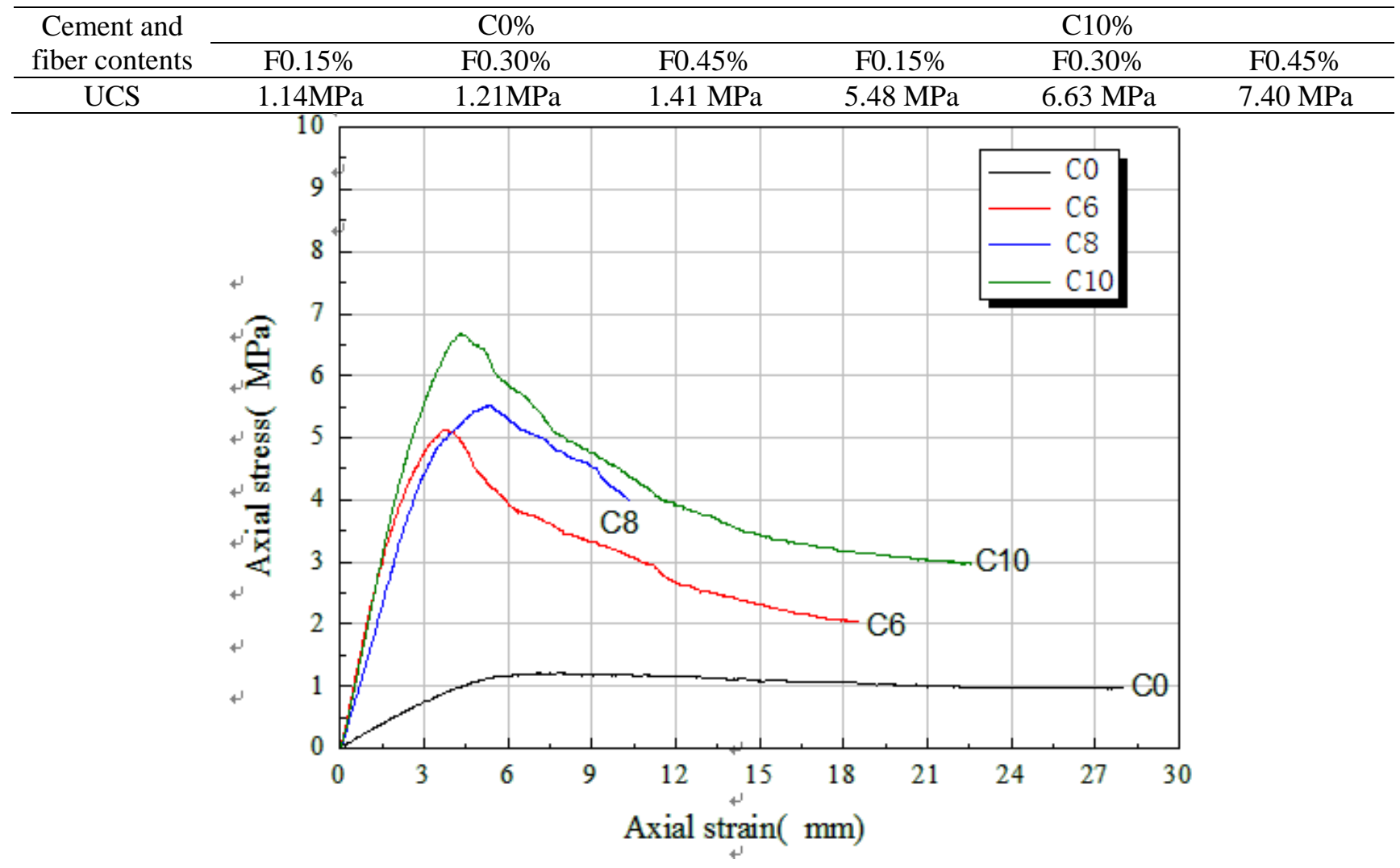

Fig. 5 The stress-strain curve of different cement contents $\left(w_{f}=3 \%\right)$

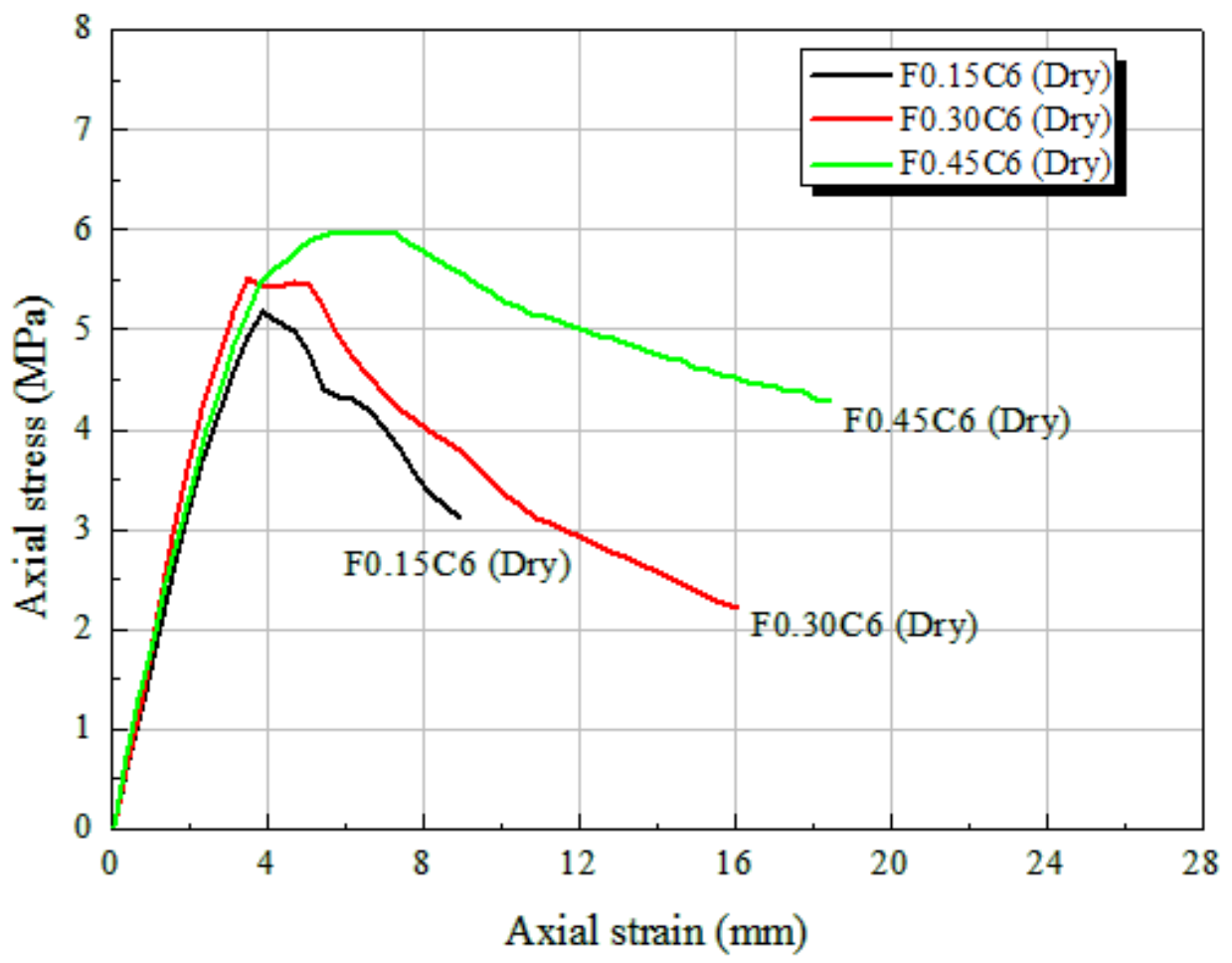

Fig. 6 The stress-strain curve of different fiber contents $\left(w_{c}=6 \%\right)$

\section{Effect of Maintaining Age on UCS}

In order to facilitate the analysis, kept fiber content $0.45 \%$ unchanged, the UCS of specimens with different cement contents and maintaining ages was tested, the affect curve of maintaining ages 
on UCS was shown in Figure 7. As seen in Figure 7, the UCS increased with the prolongation of maintaining age, however, because of the lack of cementing material, non-cement soil $\left(w_{c}=0 \%\right)$ was the exception, the UCS of non-cement soil almost unchanged.

Figure 7 indicated the faster-growing of UCS at early stage and then the growth rate slowed down gradually, take the specimen with $0.45 \%$ fiber content and $10 \%$ cement content for example, the UCS of $3 \mathrm{~d}$ dry maintaining was $5.99 \mathrm{MPa}$, which was up to $7.4 \mathrm{MPa}$ after $7 \mathrm{~d}$ dry maintaining, the growth was $23.5 \%$, and the UCS of $14 \mathrm{~d}$ dry maintaining was $8.28 \mathrm{MPa}$, the growth was $38.2 \%$.

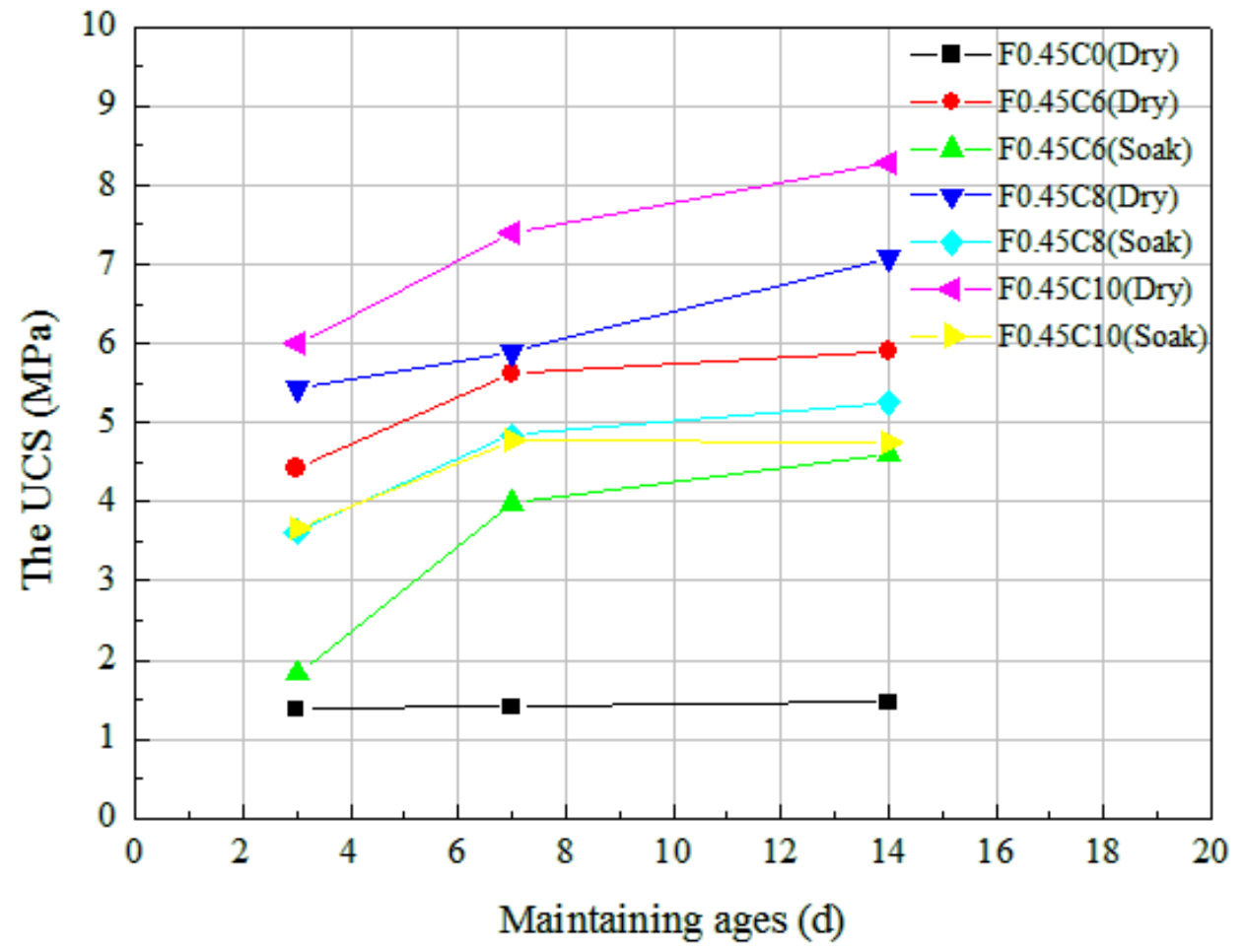

Fig. 7 The UCS of different maintaining ages

\section{The Strengthening Mechanism of MPFRCSS}

By the analysis of the test results, the incorporation of fiber and cement had obvious reinforcing effect on soil. The reinforcement included chemical effect (hydration reaction) of cement and physical effect (anti-crack effect) of fiber. After incorporated in the soil, fiber dispersed in a netlike way in the mixture, and under the influence of cementation and friction of cement, The MPFRCSS can effectively bearing the tensile stress caused by internal axial load, and reduced the stress concentration in the specimen ${ }^{[4]}$. The more fiber incorporated, the more obvious of netlike distribution characteristic it was, and the stronger ability of dispersing and transferring load it was. At the same time, the existence of fiber can effectively prevented the lateral deformation of soil.

\section{Analysis of Failure Shapes}

Failure shapes of MPFRCSS were macroscopic representation of sliding and deflection of soil particles and also were representation of emergence, development of micro crack. Therefore, it was necessary to analyze the failure shapes, as seen in Figure 8, the failure shape of pure soil, fiber only soil, cement only soil and MPFRCSS were displayed.

For pure soil and cement only soil, the crack developed and extended without obvious signs, and the characteristics of crack were long, wide and sparse, as seen in Figure 8(b,d), cracks of developed along the shear surface, and because of the brittle shear failure, the failure surface was smooth. After stripping the loose soil of tested specimens, the ring shear surface presented, as seen in Figure 8(d), the specimens were obviously inverted cone.

For fiber only soil and MPFRCSS, with the increased of load, as seen in Figure 8(a,c), the central of specimens gradually raised, and the specimens had not formed obviously failure surface at the 
end of the test, which indicated that the incorporation of fiber prevented the further development of cracks effectively. Cracks were not interconnected and the characteristics of crack were short, thin and dense., the connection effect of fiber maintained the integrity the broken specimen.

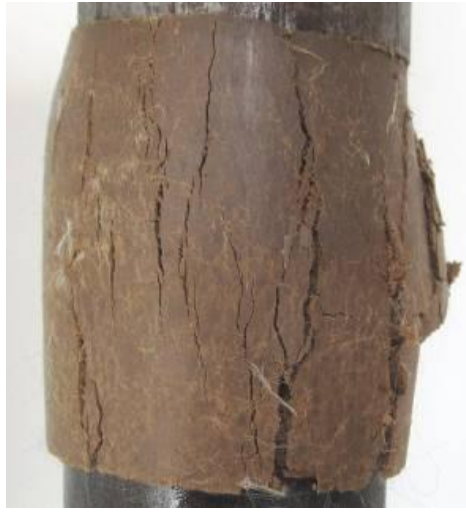

(a) Fiber only soil

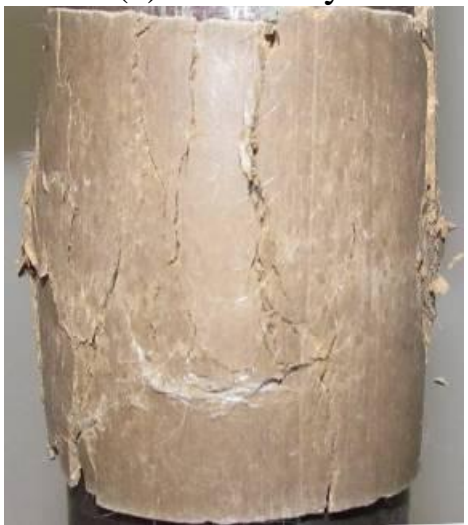

(c) MPFRCSS

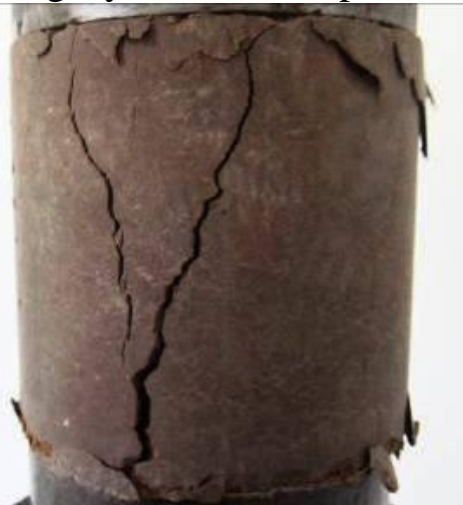

(b) Cement only soil

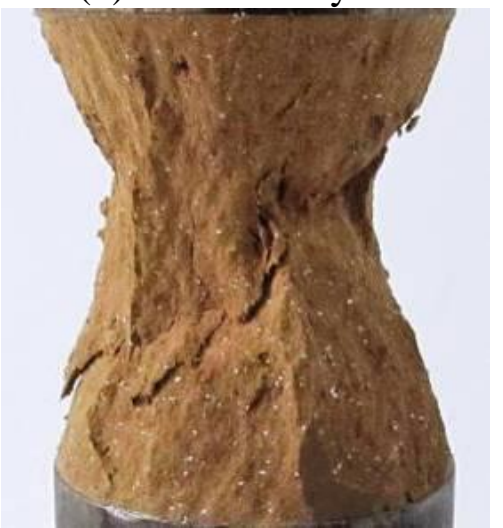

(d) Pure soil

Fig. 8 Failure shapes of soil

\section{Conclusion}

(1)The UCS of cement only soil increased with the increasing of cement contents, and the water stability greatly enhanced with the incorporation of cement, the value kept a 50 80\% growth. The stress strain curve declined rapidly soon after achieving the peak value, it indicated that the specimens presented a brittle failure characteristics

(2)The UCS of fiber only soil increased with the increasing of fiber contents, and the stress strain curve was steep, the stress increasing rate is far greater than the rate of strain, it indicated that fiber enhanced the structure strength of soil.

(3)The UCS of specimens increased with the prolongation of maintaining age, and it growed fast at early stage and then the growth rate slowed down gradually.

(4)Under the double reinforcement of fiber and cement, the USC and water stability of soil had greatly improved.

\section{References:}

[1] YIN Yong. Experimental study on mechanical properties of glass fiber improved cement soil [D]. Diss. China, Southeast University, 2006:61-66.

[2] XU Wei, CEN Guo-ping, LIN Xing-gang. Research on service performance of cement stabilized fine granular soil base course for airstrip [J]. Subgrade Engineering, 2009, 6:59-60.

[3] JTJ 034-2006. Technical Specificaitons for Construction of Highway Roadbases [S]. Beijing: China Communications Press, 2007. 
[4] TANG Chao-sheng, SHI Bin, GU Kai. Microstructural study on interfacial interactions between fiber reinforcement and soil [J]. Journal of Engineer Geology, 2011,19(4):610-614.

[5] CAI Yi, SHI Bin, GAO Wei, etc. Experimental study on engineering properties of fibre-lime treated soils [J]. Chinese Journal of Geotechnical Engineering, 2006, 28(10):1283-1287.

[6] LIU Bao-shen, TANG Chao-shen, LI Jian, etc. Advances in engineering properties of fiber reinforced soil. Journal of engineering geology, 2013, 21(4):540-547.

[7] WANG Wei, WANG Zhong-hua, ZENG Yuan, etc. Experimental study of anti-cracking and reinforcement behaviors of polypropylene fiber composite soil [J]. Rock and Soil Mechanics, 2011, 32(3):704-708.

[8] BAO Cheng-hua, DING JIN-hua. Researches and applications of fiber reinforced soils [J]. Soil Engineering and Foundation, 2012, 26(1):80-83. 